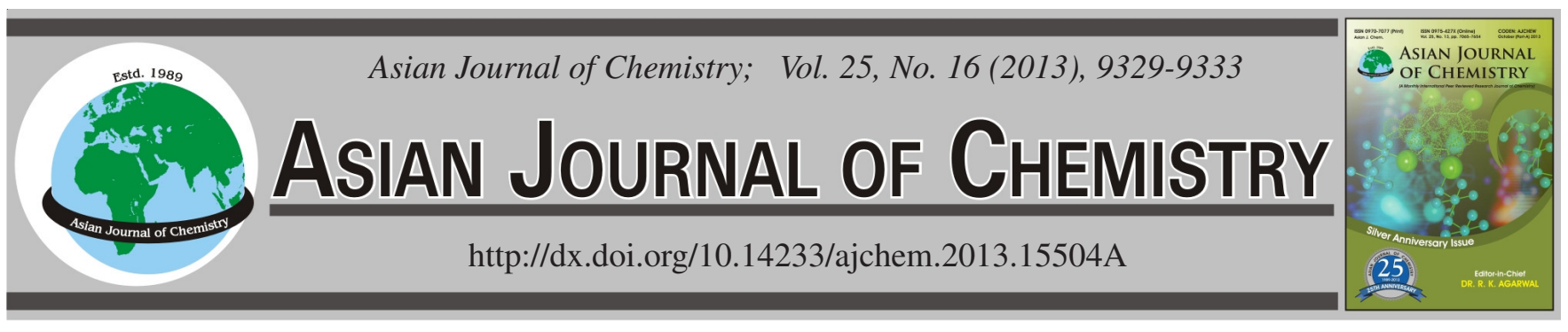

\title{
Effect of Storage Environment on the Extent of Lipid Oxidation in Peanut and Cowpea Based Infant Food
}

\author{
F.I. Bassey ${ }^{1, *}$, K.H. Mcwatters ${ }^{2}$, C.A. Edem ${ }^{1}$, M.I. Dosunmu ${ }^{1}$, Eno E. Ebenso ${ }^{3}$ and C.M.A. Iwegbue ${ }^{4}$
}

${ }^{1}$ Department of Pure and Applied Chemistry, University of Calabar, P.M.B. 1115, Calabar, Nigeria

${ }^{2}$ Department of Food Science and Technology, University of Georgia, 1109 Experiment Street, Griffin 30223-1797, Georgia

${ }^{3}$ Material Science Innovation and Modelling (MaSIM) Research Focus Area, North-West University (Mafikeng Campus), Private Bag X2046, Mmabatho 2735, South Africa

${ }^{4}$ Department of Chemistry, Delta State University, Abraka, Nigeria

*Corresponding author: E-mail: fibassey@yahoo.ca

(Received: 18 March 2013;

Accepted: 23 September 2013)

AJC-14171

The combined effect of storage temperature, relative humidity and available packaging materials on the lipid oxidative stability of peanut
and cowpea based weaning food was investigated. Samples were prepared and stored in glass jars and polyethylene bags at 20,30 and
$40{ }^{\circ} \mathrm{C}$, respectively for 3 months. The zip-loc bag samples were stored at $75 \%$ relative humidity to simulate the relative humidity in
tropical regions of West Africa. The extent of lipid oxidation was measured via the level of hexanal liberation using automated head space
solid-phase micro-extraction gas chromatography (auto HS-SPME-GC). It was observed that water vapor permeability of the polyethyl-
ene bag samples resulted in increased moisture content (from 4.42 to $7.80 \%$ ) and water activity (from 0.22 to 0.48 ) with storage-time and
temperature. These increases were observed to adversely influence oxidative stability of the novel food as hexanal production increased
from 5.45 to $13.794 \mathrm{ppm}$ at $30^{\circ} \mathrm{C}$ in week 8 for sample stored in polyethylene bag. It was also observed that lipid oxidation was negligible
within the first 8 weeks of storage for samples protected from moisture exchange (glass jar) at all storage temperatures as seen in the
negligible levels of moisture content and water activity. Hexanal content of the glass jar samples was within the range of 5.45 and 33 ppm
in the first 8 weeks. Results further showed that sample stored in glass jar at $40{ }^{\circ} \mathrm{C}$ liberated the lowest level of hexanal (19.33 ppm)
compared to values of 30.33 and 33 ppm liberated at 30 and $20{ }^{\circ} \mathrm{C}$, respectively at the end of 8 weeks. The weaning food stored in moisture
barrier system can therefore be expected to achieve reasonable shelf stability within the desired short storage period without the extra cost
of antioxidants.

Key Words: Infant food, Cowpea, Peanut, Lipid oxidation, Hexanal.

\section{INTRODUCTION}

The susceptibility of lipids to oxidation has been extensively documented as a limiting factor in the shelf stability of processed and natural foods like peanuts, nuts, cookies and powdered milk $^{1-3}$. Peroxidation occurs as oxygen reacts with unsaturated lipids, leading to subsequent breakdown, generating undesirable carbonyls, aldehydes and ketones ${ }^{4,5}$. One of the most important products of these reactions is hexanal which has become a popular indicator of lipid oxidation in foods ${ }^{6}$. It is one of the dominant volatile secondary products formed during the oxidation of linoleic $\mathrm{acid}^{7}$. The final consequences of lipid oxidation are development of off-flavours and/ or changes in texture, colour, water holding capacity, nutritive properties and potentially toxic reaction products. There is need for an effective study of lipid oxidation to predict the shelf life of whole foods in order to protect consumers from consumption of final products of lipid oxidation, to promote healthy food products; as well as, for economic purposes ${ }^{2,8-10}$.

Several accelerated deteriorative conditions have been documented to predict the resistance of edible oils and whole foods with regards to oxidation ${ }^{11,12}$. These tests often use controlled chambers to store foods under accelerated deteriorative conditions, such as high temperature, oxygen, light and relative humidity ${ }^{13}$. This is carried out in order to evaluate the extent to which the variety of extrinsic factors among which are storage conditions; packaging material, exposure to light, air and heat, etc. ${ }^{1,2,14}$ which define lipid oxidation rates influence the rate of this reaction in foods.

Reaction rates in foods have been known to increase exponentially with increase in temperature ${ }^{15}$. Storage temperature is a very important factor that affects shelf-stability, regardless of the type of processing involved. Chemical reactions are known to quadruple in some cases for a $10^{\circ} \mathrm{C}$ 
rise in temperature ${ }^{15}$. For example, only 5-15\% of vitamin C is lost when canned foods are stored for up to one year at $65 \mathrm{~F}$ $\left(18^{\circ} \mathrm{C}\right)$, but when stored at $80 \mathrm{~F}\left(26.7^{\circ} \mathrm{C}\right)$ in the warehouse losses can be up to $15-30 \%$. The relative humidity of the immediate environment is also known to directly affect the moisture content and water activity $\left(\mathrm{a}_{\mathrm{w}}\right)$ of food which in turn affects the rate of lipid oxidation. It has also been reported that the rate of lipid oxidation also increases with increasing $\mathrm{pH}^{16,17}$ whereas others have found the opposite-on seemingly similar systems ${ }^{18}$.

Development of fatty foods with sustained nutritional and physical attributes therefore depends on the availability of methods of controlling oxidative stability. This can be achieved by the application of antioxidants and the use of proper packaging material ${ }^{13}$. The bottleneck with synthetic antioxidant is the wide unacceptability by consumers, as they have been incriminated in cancer and other unidentified health disorders ${ }^{19,20}$ while naturally occurring antioxidants have been documented to pose a number of practical problems including the high costs of production in useful amounts and in many cases flavours that while desirable in some foods will be unwelcome in others ${ }^{21}$. The possibility of applying or using natural antioxidants for the preservation of weaning foods targeted at meeting the nutritional needs of children whose parents are low income earners in developing West African countries will probably defy the possible use of these foods by the targeted group due to the increased cost of production.

The objective of the present study was to assess the effects of storage temperature, relative humidity and available packaging materials (without the use of antioxidants) on the extent of lipid oxidation in a novel weaning food processed from cooking banana, supplemented with peanut and cowpea aimed at serving as a transition infant diet for a majority of the populace who are low income earners, in developing west African countries, particularly in Nigeria. This is carried out in order to determine the best storage conditions that enhance the shelf stability of the novel food without additional production costs.

\section{EXPERIMENTAL}

A ready-to-eat weaning food was prepared according to the method of Bassey ${ }^{22}$ and stored in sealed containers at $-18^{\circ} \mathrm{C}$ in a walk in storage chamber. A total of $8,890 \mathrm{~g}$ of sample was divided into two equal weights. Each half was further divided into nine equal weights $(493.88 \mathrm{~g})$. The first half was placed in nine medium density polyethylene bags and the other half in nine air tight glass jars to simulate two different packaging systems. In order to investigate the effect of temperature and relative humidity, three different storage chambers- (model OV 510A-3, Lindberg/Blue M, Blue Island, IL USA) were used with temperatures pre set to 20,30 and $40{ }^{\circ} \mathrm{C}$, respectively. Constant relative humidity of $75 \%$ was created with the aid of a saturated solution of sodium chloride. This was done to simulate the relative humidity in tropical regions of West Africa. Samples were placed on a perforated rack over the saturated salt solution in a sealed plastic container. Each of the sets (the polyethylene bag and glass jar samples stored at different storage temperatures) was brought out every 4 weeks for analysis of different parameters. All the samples were labeled for easy identification.

Hexanal measurement: A working standard was prepared by placing $4.85 \mathrm{~mL}$ of canola oil in a test tube to which 0.15 $\mathrm{mL}$ of heptanone was added and the mixture vortexed for $30 \mathrm{~s}$. The mixture was placed in a test tube holder until the liquid became clear before use. $2 \mathrm{~g}$ of sample were placed in the vial and $5 \mathrm{~mL}$ of $30 \mathrm{ppm}$ heptanone working standard was added. The sample was then heated in a thermolyne dri-bath, for 15 min. The needle was kept at $0.8 \mu \mathrm{m}$ prior to piercing into the vial and rolled up to $1.6 \mu \mathrm{m}$. The fiber was then exposed to the sample for $0.5 \mathrm{~h}$, drawn back into the needle in the fiber holder and the needle rolled out to its complete length, pierced through the septum at the same spot each time on the gas chromatogram (GC) (Varian Star 3400 CX, Walnut Creek, California. USA) to avoid septum leakage. The fiber was then exposed in the system for $5 \mathrm{~min}$; a total of $17 \mathrm{~min}$ run time was used. The measurements were carried out in triplicate (Table-2).

Vitamin and fatty acids analyses: Vitamins A, E and fatty acids were analyzed by Silliker Labs (Homewood, CA). USA.

Water activity: The water activity was determined by the method of Murphy et $a l .^{23}$ using a water activity meter (Aqua lab, model 3TE, Decagon Devices Inc., Pullman, Washington, USA). Each sample (2 g) was weighed into the measurement dish; the dish was placed in the drawer of the unit and the meter turned on. The measurements were conducted at room temperature. Measurement of each sample was done in triplicate.

pH: pH was measured using the method of Murphy et $a l .^{23}$ with the aid of an AR $15 \mathrm{pH}$ meter (Accumet Research, Fisher Scientific, Pittsburgh, Pennsylvania, USA). Each sample $(2 \mathrm{~g})$ was mixed with $20 \mathrm{~mL}$ distilled water and shaken mechanically for $5 \mathrm{~min}$. The $\mathrm{pH}$ of each sample was then determined in triplicate.

Moisture content: The moisture was analyzed according to the method of the Association of Official Analytical Chemists $(\mathrm{AOAC})^{24}$. An Isotemp vacuum oven (model 281A, Fisher Scientific, Pittsburgh, Pennsylvania, USA) was used to determine moisture content. Three grammes $(3 \mathrm{~g})$ of sample was weighed into a pre-dried aluminium weighing dish and covered with a lid. This was then placed in the oven for $14 \mathrm{~h}$ with the temperature and pressure kept at $105^{\circ} \mathrm{C}$ and $25 \mathrm{~mm} \mathrm{Hg}$, respectively. The sample was transferred to a dessicator with the aid of a Kimwipe to cool and then weighed. The residue was recorded as total solids and stored in a dessicator for fat analysis while percentage moisture was calculated from loss in weight by the following formula:

$$
\text { Moisture }(\%)=\frac{\text { Loss in wt. }}{\text { wt of sample }} \times 100
$$

Each sample was analyzed in triplicate.

Data: All the data were analyzed statistically with the aid of the Statistical Analysis Software (SAS, 1990) ${ }^{25}$. Fisher's least significant difference test (LSD) was performed to determine which sample's means were significantly different, Difference were considered significant at $p \leq 0.05$ level. 


\section{RESULTS AND DISCUSSION}

The extent of lipid oxidation in cooking banana, peanut and cowpea based weaning food as influenced by storage temperature, relative humidity and available packaging was measured via the level of hexanal liberation using automated head space solid-phase micro-extraction gas chromatography (auto HS-SPME-GC).

Oxidative stability of the sample was examined for 12 weeks and at different temperatures (Figs. 1 and 2). Hexanal significantly increased $(p \leq 0.05)$ from 5.45 at the beginning of the study to $13,794.7 \mathrm{ppm}$ at the end of 8 weeks for samples stored in polyethylene bags at $30^{\circ} \mathrm{C}$ and further decreased to $6317 \mathrm{ppm}$ at the end of the study at the same storage temperature. Lower increases were observed for samples stored in both polyethylene bags and glass jars for all storage conditions within the first 4 weeks. Values of 6.14, 5.9 and $7.12 \mathrm{ppm}$ was recorded at the end of 4 weeks for samples stored in glass jars while 34,09, 27.79 and $38.61 \mathrm{ppm}$ was recorded for the polyethylene bag samples within the same storage period.
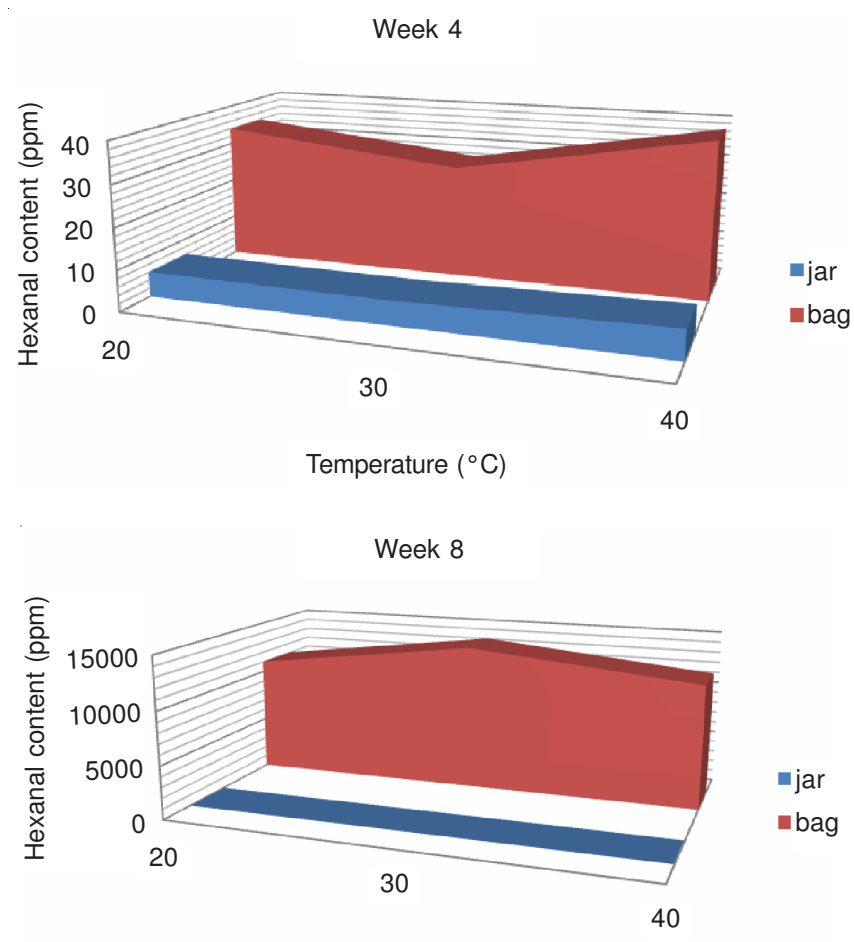

Temperature $\left({ }^{\circ} \mathrm{C}\right)$

Week 12

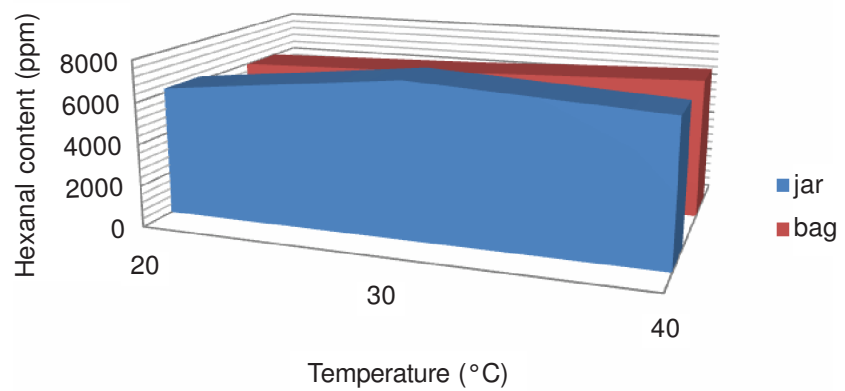

Fig. 1. Effect of temperature on hexanal content of sample stored in jar and zip-loc bag for 4, 8 and 12 weeks $20^{\circ} \mathrm{C}$

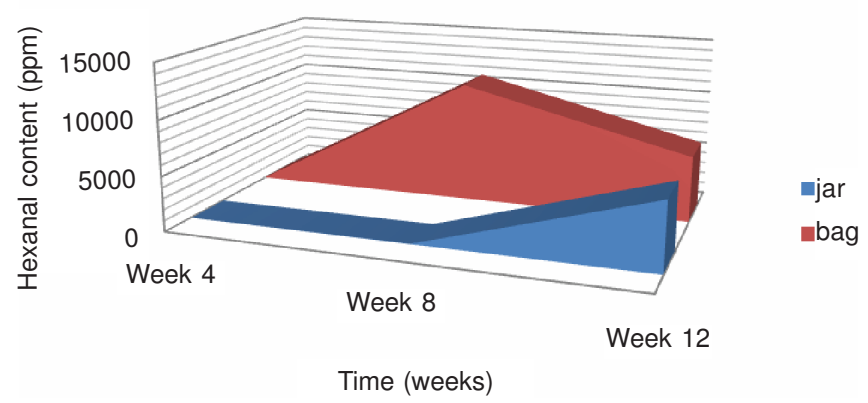

$30{ }^{\circ} \mathrm{C}$

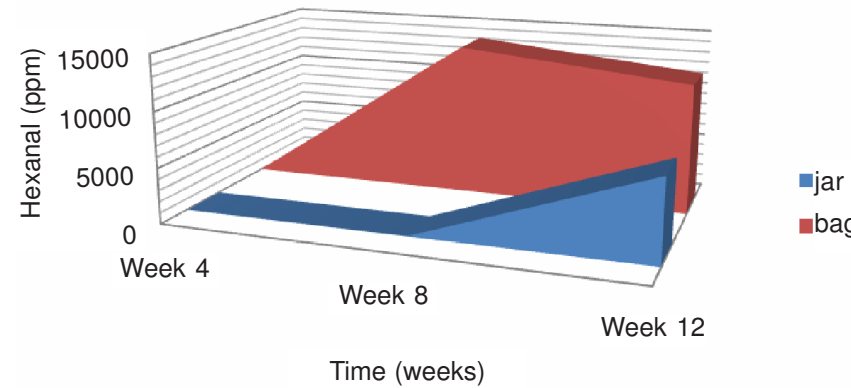

$40^{\circ} \mathrm{C}$

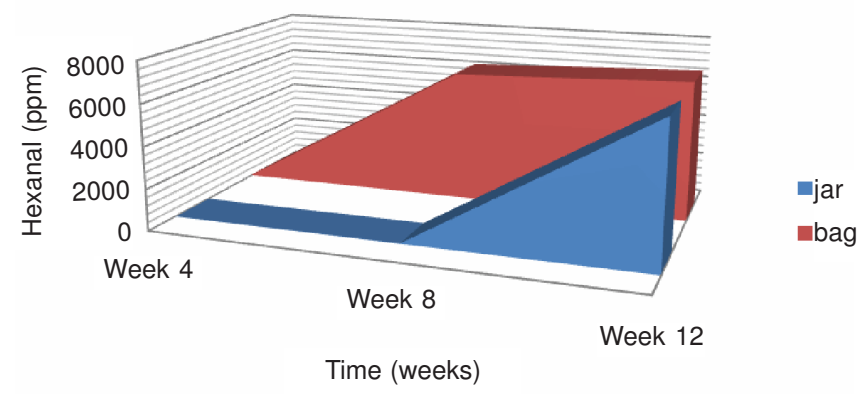

Fig. 2. Variation in hexanal content of sample stored in (a) jar and (b) polyethylene bag at 2030 and $40{ }^{\circ} \mathrm{C}$

There was significant difference in the oxidative stability of samples protected from moisture uptake (glass jars) and unprotected sample (polyethylene bags). Sample stored in ziploc bags oxidized faster resulting in a shorter shelf life. Oxygen and water vapor permeability of flexible packaging materials are two factors which limit the shelf-stability of dry foods with high oil content ${ }^{26}$. It is common practice to use vacuum packaging or inert gas flushing for the prevention of oxygen effects $^{27}$. Since the polyethylene bags used in this study were sealed without vacuum and inert gas flush, the effects of oxygen and other factors were assumed to be the same for all samples but the problem of moisture gain and increased water activity was examined. Table- 2 shows the increases in moisture and water activity of weaning food in polyethylene bags at an environment of $75 \%$ relative humidity at different temperatures. It was observed that water vapor permeability of the polyethylene bag samples resulted in increased moisture content (from 4.42-7.80\%) and water activity (from 0.22-0.48) with storage-time and temperature. These increases were observed to adversely influence oxidative stability of the novel food as 
TABLE-1

VARIATION IN VITAMINS C AND E CONTENT OF WEANING FOOD AFTER 12 WEEKS ATDIFFERENT TEMPERATURES

\begin{tabular}{cccccccc}
\hline & 0 day & 12 week & 12 week & 12 week & 12 week & \multicolumn{1}{c}{12 week } & 12 week \\
\cline { 2 - 8 } & & $20{ }^{\circ} \mathrm{C}($ jar $)$ & $30{ }^{\circ} \mathrm{C}($ jar $)$ & $40{ }^{\circ} \mathrm{C}($ jar $)$ & $20{ }^{\circ} \mathrm{C}(\mathrm{bag})$ & $30{ }^{\circ} \mathrm{C}(\mathrm{bag})$ & $40^{\circ} \mathrm{C}(\mathrm{bag})$ \\
\hline Vitamin $\mathrm{C}(\mathrm{mg})$ & 1.54 & $<1.0$ & $<1.0$ & $<1.0$ & $<1.0$ & $<1.0$ & $<1.0$ \\
Vitamin E(iu) & .84 & 0.5 & 0.4 & 0.5 & 0.4 & 0.4 & 0.5 \\
\hline
\end{tabular}

TABLE-2

VARIATION IN HEXANAL CONTENT AT DIFFERENT MOISTURE, WATER ACTIVITY AND pH LEVELS

\begin{tabular}{|c|c|c|c|c|c|c|}
\hline Time & Bagging & Temp. $\left({ }^{\circ} \mathrm{C}\right)$ & Hexanal & Moisture & Aw & $\mathrm{pH}$ \\
\hline 0 week & Jar & 20 & 5.45 & 4.42 & 0.22 & 5.72 \\
\hline 4th week & Jar & 20 & 6.14 & 4.32 & 0.22 & 5.72 \\
\hline 4th week & Jar & 30 & 5.9 & 4.93 & 0.22 & 5.71 \\
\hline 4th week & Jar & 40 & 7.12 & 4.34 & 0.19 & 5.72 \\
\hline 4th week & zip-loc bag & 20 & 34.09 & 5.26 & 0.26 & 5.74 \\
\hline 4th week & zip-loc bag & 30 & 27.79 & 4.31 & 0.18 & 5.71 \\
\hline 4th week & zip-loc bag & 40 & 38.61 & 6.05 & 0.33 & 5.7 \\
\hline 8th week & Jar & 30 & 30.33 & 4.95 & 0.26 & 5.91 \\
\hline 8th week & Jar & 40 & 19.33 & 4.21 & 0.18 & 5.88 \\
\hline 8th week & zip-loc bag & 20 & 11049 & 5.75 & 0.35 & 5.89 \\
\hline 8th week & zip-loc bag & 30 & 13794.7 & 4.24 & 0.19 & 5.87 \\
\hline 8th week & zip-loc bag & 40 & 11712 & 7.01 & 0.47 & 5.64 \\
\hline 12th week & Jar & 20 & 6203 & 3.67 & 0.19 & 5.7 \\
\hline 12th week & Jar & 30 & 7435.67 & 5.08 & 0.28 & 5.67 \\
\hline 12th week & zip-loc bag & 20 & 5999.33 & 6.11 & 0.38 & 5.74 \\
\hline 12th week & zip-loc bag & 30 & 6317 & 4.01 & 0.21 & 5.71 \\
\hline 12th week & zip-loc bag & 40 & 6725 & 7.8 & 0.49 & 5.62 \\
\hline
\end{tabular}

hexanal production increased from $5.45-13,794 \mathrm{ppm}$ at $30^{\circ} \mathrm{C}$ in week 8 for sample stored in zip-loc bag compared to hexanal content of samples in jar which ranged between 19.33 and $33.0 \mathrm{ppm}$. Hexanal was observed to increase at a slow rate in samples stored in jar within the first 8 weeks for all storage conditions. A decrease by an average of approximately $50 \%$ from week 8 to week 12 was recorded for samples stored in polyethylene bags at all temperatures. On the other hand multiple increases were observed for samples stored in the glass jars within the same period. This could be attributed to the antioxidant activity of competing Maillard browning reaction which is favoured at high temperatures, high moisture content and high water activity.

Temperature was observed to have varying effect on the rate of lipid oxidation of the samples with storage time. At the end of the 4th week, high temperature $\left(40^{\circ} \mathrm{C}\right)$ was observed to result in increased hexanal content while a different trend was observed for samples within the 8th and 12th week of storage. At the end of week 8 , sample stored in jar at $40{ }^{\circ} \mathrm{C}$ was observed to have yielded the least amount of hexanal (19.33 ppm), compared with values of 30.33 and $33.00 \mathrm{ppm}$ for 30 and $20^{\circ} \mathrm{C}$, respectively. At $20^{\circ} \mathrm{C}$ on the other hand the least hexanal content for samples stored in both jar and bags was obtained. Samples stored in both polyethylene bag and glass jar at $40^{\circ} \mathrm{C}$ were observed to liberate the highest amount of hexanal at the end of the study. Effect of high temperature on the shelf stability of peanut products has also been documented $^{26,28}$.

Fig. 1 shows that hexanal content was very low (less than 8 and $40 \mathrm{ppm}$ for samples stored in jar and polyethylene bags, respectively) in the first 4 weeks of the study and increased significantly $(p \geq 0.05)$ midway during storage to $13,794.67$ ppm at the end of 8th week for samples stored in polyethylene bags at $30{ }^{\circ} \mathrm{C}$. The observed increase in amount of hexanal liberated midway in the shelf-life study could be attributed to ascorbic acid degradation which rendered ascorbic acid unavailable to act as an antioxidant. Since scavengers work well at relative humidity above $50 \%$, the decrease in ascorbic acid to a near zero level (Table-1) can be attributed to its participation in the inhibition of autoxidation reactions at the initial storage period. Hence when completely used up, an increase in hexanal content was observed.

Hexanal content was observed to decrease from 13,794.67 ppm (value at $8 \mathrm{wk}$ ) to $5,999.33 \mathrm{ppm}$ (over $50 \%$ decreases) at the end of the study. This result suggests an onset of Maillard reaction which is known to act as antioxidant thereby inhibiting/ retarding oxidation reaction. Maillard reaction is favoured at high temperatures with increased storage time and the presence of all reactants required for Maillard browning; an amino bearing compound (protein), a reducing sugar (D-glucose) and water. The antioxidant activity of non-enzymatic browning reaction products have been documented ${ }^{29}$. Lee et al. ${ }^{30}$ have also reported antioxidant activity of Maillard reaction products as inhibitors of lipid oxidation. Bressa et al. ${ }^{31}$ also recorded that the addition of sugar and/or amino acids to baked foods, such as cookies was observed to enhance the browning reaction of butter cookie and subsequently increase its stability against oxidative rancidity.

Some workers ${ }^{16,17}$ have also found out that the rate of lipid oxidation increases with increasing $\mathrm{pH}$ whereas others have found the opposite-in seemingly similar systems ${ }^{18}$.

Increased moisture as influenced by storage conditions was observed to lead to significant increase in water activity of samples, while decreases also resulted in decreases in water 
activity of samples. Water is known to act as both a pro-oxidant and an antioxidant depending on the water activity of the product $^{32}$. Results show increased hexanal content with increase in moisture and water activity, signifying increased lipid oxidation of the product. Lipid oxidation was observed to proceed more slowly at intermediate water activity range but increased rapidly at both high and low levels. Felland and Koehler ${ }^{28}$ in their work on peanut butter noted an onset of lipid oxidation with increased moisture and water activity. The effect of moisture content and water activity on lipid oxidation rates agrees with other studies where the lowest rate of oxidation was found at intermediate water activities ${ }^{26,28,32}$.

\section{Conclusion}

Oxidative stability of cooking banana, peanut and cowpea based infant food as influenced by its storage environment was investigated. The extent of lipid oxidation was measured via the level of hexanal liberation using automated head space solid-phase micro-extraction gas chromatography (auto HSSPME-GC). Within the experimental conditions in this study, it was observed that water vapor permeability of the zip-loc bag samples resulted in increased moisture content (from 4.42 to $7.80 \%$ ) and water activity (from 0.22 to 0.48 ) with storagetime and temperature. These increases were linked to the low oxidative stability of the infant food as seen in increase in hexanal production from $5.45 \mathrm{ppm}$ at week $0-13,794 \mathrm{ppm}$ at $40{ }^{\circ} \mathrm{C}$ in week 8 .

It was also observed that samples stored in glass jars prevented moisture exchange within the storage environment hence the storage of the novel weaning food in moisture barrier systems will be expected to enhance the stability of the product in these regions known to have high \%. Relative humidity and temperature. The weaning food stored in moisture barrier system can therefore be expected to achieve reasonable shelf stability without the extra cost of antioxidants. Increasing the concentration of lime juice employed in the processing of the weaning food could be explored with a view to delaying the onset of lipid oxidation hence enhancing the shelf stability.

The processing, packaging and storing of a novel weaning food without the use of antioxidants were accessed. This was done in order to evaluate the possibility of using inexpensive but available technology, to_process and preserve within an estimated period which allows the targeted low income earners to access and use the product for their infants. This is carried out with the ultimate aim of providing an intervention vehicle to combat malnutrition and infant mortality in a developing country like Nigeria resulting from the inability of a majority of the populace (who are low income earners) to afford and use proprietary weaning foods for their babies.

\section{ACKNOWLEDGEMENTS}

The authors are grateful to Larry Hitchcock, Sue Ellen McCullough, Sandra Walker, Glenn Farrell and Firibu Saalia for technical assistance.

\section{REFERENCES}

1. F. Mestdagh, D. Meulenaer, J. De Clippeleer, F. Devlieghere, A. Huyghebaert, J. Dairy Sci., 88, 499 (2004).

2. S. Calligaris, L. Monzocco, L.S. Conte and M.C. Nicoli, J. Food Sci., 69, E361 (2004).

3. S. Calligaris, L. Monzocco, G. Kravinna, L.S. Conte, M.C. Nicoli, J. Agric. Food Chem., 55, 2004 (2007).

4. N.R. Grosso and A.V.A. Ressurreccion, J. Food Sci., 67, 1530 (2002).

5. E. Choe, D.B. Min, Comp. Rev. Food Sci. Food Safety, 5, 169 (2006).

6. N.A. Porter, S.E. Caldwell, K.A. Mills, S.E. Caldwell and K.A. Mills, Lipids, 30, 277 (1995).

7. F. Shahidi and R.B. Pegg, In ed.: A.J. St Angelo, Hexanal as an Indicator of the Flavour Deterioration in Meat and Meat Products, Lipid Oxidation in Food; ACS Symposium Series 500; American Chemical Society, Washington (1994).

8. A. Vercet, Food Chem., 8, 371 (2003).

9. R. Vidal-Quintanar, M.H. Love, J.A. Love, P.J. White and L.A. Johnson, J Food Lipids, 10, 153 (2003).

10. K. Vankerschaver, F. Willocx, M. Smout, M. Hendrickx and P. Tobbach, J. Food Sci., 61, 1094 (1996).

11. J.C. Anderson and B.D. Jones, J. Food Sci., 64, 1059 (1999).

12. R. Farhoosh, J. Am. Oil Chem. Soc. Int., 84, 205 (2007).

13. P.R. Pike, E. Abdel-Aal and A. McElroy, J. Am Oil Chem. Soc., 84, 663 (2007).

14. S. Ozilgen and M. Ozilgen, J. Food Sci., 55, 498 (1990).

15. J.O. Ragnarsson and T.P. Labuza, Food Chem., 2, 291 (1977).

16. S.W. Huang, N. Frankel, R. Aeschbach and J.B. German, J. Agric. Food Chem., 45, 1991 (1997).

17. J.R. Mancuso, D.J. Mc-Clements and E.A. Decker, J. Agric. Food Chem., 47, 4112 (1999).

18. J.T. Donnelly, E.A. Deckker and D.J. McClements, J. Food Sci., 63, 997 (1998).

19. S.N. Onyeneho and N.S. Hettiarachchy, J. Agric. Food Chem., 39, 1701 (1991).

20. D.L. King, T.S. Hahm and D.B. Min, In ed.: G. Charalambous, Chemistry of Antioxidants in Relation to Shelf Life of Foods, Shelf Life Studies of Foods and Beverages, Amsterdam: Elservier Science Publisher B.V. pp. 629-705 (1993).

21. T.P. Coultate, Food: The Chemistry of its Components (2002).

22. F.I. Bassey, Ph.D. Thesis, Chemical Composition, Functional Properties and Shelf-life of Weaning Food Processed from Cooking Banana, Department of Pure and Applied Chemistry, University of Calabar, Calabar, Nigeria (2005).

23. M.G. Murphy, D.I. Skonberg and M.E. Camire, J. Sci. Food Agric., 83, 1163 (2003).

24. AOAC International, Official Methods of Analysis, Arlington: AOAC International, edn. 16 (1995).

25. SAS 1990. SAS/START User's Guide, Version 6, Cary, NC: Statistical Analysis Systems Institute, Inc., edn. 4, Vol. 2.

26. E.E. Ozgul, Eur. J. Lipid Sci. Technol., 59, 189 (2000).

27. C.G. Cavaletto and H.Y. Yamamoto, Food Technol., 22, 97 (1968).

28. S.L. Felland and P.E. Koehler, J. Food Quality, 20, 145 (1996).

29. F.J. Morales and S. Jimenz-perez, Food Chem., 72, 119 (2001).

30. Y.C. Lee, I.H. Kim, J. Chong, Y.K. Rhee, I.H. OH and H.K. Park, J. Food Sci, 69, 33 (2004).

31. F. Bressa, N. Tesson, M. Dallarosa, A.F. Sensidoni and F. Tubaro, $J$. Agric. Food Chem., 44, 692 (1996).

32. A.J. Fontana, Cereal Food World, 45, 7 (2000). 